\title{
Jehona e periudhës së Skënderbeut në krijimet popullore të Elbasanit
}

\author{
Qemal Haxhihasani
}

Një nga trevat ku u ruajt lavdia e periudhës së Skenderbeut nëpër krijimet tradicionale ka qenë edhe Elbasani. Në këtë trevë, siç dëshmojnë dokumentet e kohës, u shtjelluan ngjarje të rëndësishme. Që në vitet '30 të shekullit XV, me Arianitin, këtu ish ngritur një barrikadë e fuqishme kundër rrebeshit turk që po përpiqej të vërshonte mbi vendin tonë. Këto përpjekje të ushtrisë osmane për pushtimin e Shqipërisë, morën një hov të veçantë në kohën e Skënderbeut, kur qëllimet e sulltanëve turq për nënshtrimin e plotë të Ballkanit dhe kapërcimi në perëndim po bëheshin gjithmonë e më këmbëngulëse. Më 1466, Mehmeti II rindërtoi kështjellën e Valmit. Shënimet e kronistëve osmanë e bizantinë rreth kujdesjeve të sulltan Mehmetit për ngritjen e kësaj kështjelle, vetë njoftimi i bujshëm që i bën ky sulltan ambicioz të birit, Bajazitit për funksionet e saj, tregojnë se ç'rëndësi kishin përgatitjet dhe veprimet ushtarake turke që ishin përqendruar në këtë trevë. Po për një fakt të tillë flasin edhe burime të tjera historike me të dhënat që na sjellin rreth luftimeve në grykën e Shkumbinit, rreth ngjarjeve të ndryshme për valmoret, arianitët, sopotarët, brateshkozanet, Kërrabën e Byshekun, për përgatitjet ushtarake të Skëndërbeut lidhur me shkuljen e armikut nga Valmi etj.

Është e kuptueshme se këto ngjarje nuk kishin se si të kalonin pa jehonë në kujtesën e popullit, pa u fiksuar në krijimet artistike tradicionale të tij. Kur shkojmë sot nëpër krahinat e ndryshme të rrethit tonë, na dalin përpara si lapidar lavdie toponime që mbajnë emrin e heroit si: Shkalla e Skënderbeut në Rrajcë, Sofra e Skënderbeut në Pishkash, Shpella e Skënderbeut në Qukës, 
Guri i Skënderbeut në Dardhë, Vgjollat e Skënderbeut në Labinot, Gjurma e kalit a e mushkës së Skenderbeut në Bërzeshtë, Floq, Mirakë, Prapanikë, Griqan, Cërujë. Kudo në këto zona jeton nëpër zërin e traditës madhështia e asaj periudhe epike, kur masat tona popullore të udhëhequra nga heroi ynë vigan Gjergj Kastrioti Skëndërbeu, ditën të përballojnë me guxim dhe vendosmëri të rrallë rrezikun e një armiku të fuqishëm që kërcënonte, jo vetëm lirinë e popullit tonë dhe të popujve të tjerë të Ballkanit, por edhe vlerat themelore të qytetërimit europian.

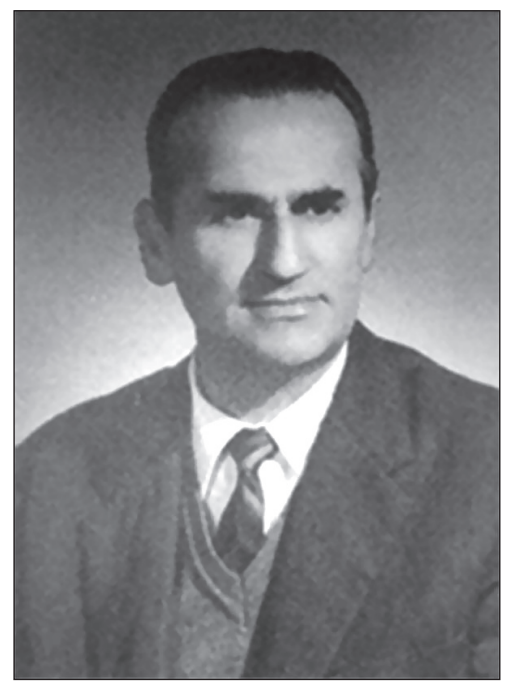

Kujtimet e kësaj periudhe të lavdishme, me gjithë kushtet e rënda të pushtimit turk, u ruajtën përmes shekujve si një thesar i shtrenjtë i ndërgjegjes sonë kombëtare duke u përcjellë gojë më gojë nga nji brez në tjetrin deri në ditët tona. Elementet e para të kësaj tradite u bënë të njohura në shtyp që në fillim të këtij shekulli. Në kalendarin kombëtar të vitit 1901 u botuan disa legjenda të mbledhura në Bixëllenjë, Preçë e Mollagjesh (këto mund të quhen njëkohësisht edhe elementet e para të botuara nga tradita popullore për Skëndërbeun në përgjithësi). Më vonë në revistën Kopështi Letrar (1918-1919) u përmblodhën gojëdhënat rreth Sopotit, Gjorg Golemit, Peter Petroshit etj. Më 1938 u bë e njohur në revistën Shkolla Kombëtare, kënga e luftimeve të Gjorg Golemit në Sopot, ndërsa më 1944 u dhanë në vëllimin XIII të Visareve të Kombit disa gojëdhëna të Shushicës, Shpatit dhe Mollagjeshit. Këtyre elementeve të trashëguara nga periudha e para çlirimit (rreth 15 legjenda gjithsej), iu shtuan nga 120 elemente të reja të mbledhura pas çlirimit me kërkimet sistematike që u bënë në krahinat e ndryshme të trevës sonë. Mund të thuhet se këto materiale japin një ide deri diku të qartë për kushtet në të cilat jeton tradita gojore e periudhës së Skenderbeut në këtë trevë, për përhapjen, tematikën dhe problemet e ndryshme që mund të ngrihen lidhur me studimin e saj.

Gojëdhëna të Skënderbeut dhe të bashkohësve të tij, jetojnë në grykën e Zaranikës dhe në anën lindore të Kërrabës: Mollagjesh, Preçe, Cërujë, Gur i Zi, Rrilë, Bixillënje, Gjorem, Kozan, Baltëz; në fshatra të zonës verilindore të Elbasanit dhe në ato të krahinës në Çermenikë: Godolesh, Labinot, Griqan, 


\section{Albanon}

Revistë kulturore

Prapanike, Mirakë, Shmil, Gurakuq, Floq, Kostenjë, Lunik; në luginën e Shkumbinit: Rrajë, Pishkash, Bërzeshtë, Farret, Qukës, Babje, Sopot, Polis, Shushicë; në Shpat: Mlizë, Shelcan, Dërstilë, Gjinar, Valësh, Zavalinë, Nezhan, Seltë; në ndonji fshat të rrethit të Gramshit si në Galigat, Tervol, Shenapremte.

Nga kjo paraqitje sado e shpejtë, kuptohet se Elbasani dallohet si një trevë shumë e pasur për legjendat e Skënderbeut, që mund të krahasohet me vatrat më të rëndësishme të kësaj tradite - me Matin, Krujën e Dibrën. Një pasuri e tillë nuk është e rastit, as e huajtur nga krahina të tjera. Ajo kushtëzohet nga ngjarjet historike dhe veprimtaria e gjallë luftarake që u zhvillua në këtë trevë.

Vlen të përmendet që në fillim fakti se në legjendat tona, krahas figurës qendrore të heroit kombëtar Gjergj Kastriotit, Skënderbeut, jeton me përpjestime të veçanta edhe ajo e Gjorg Golemit, që është identifikuar si vjehrri i heroit, Gjergj Arianiti. Gojëdhënat për këto dy protagonistë të mëdhenj të ngjarjeve tona të shek. XV shtrihen në terrene të caktuara të Skënderbeut, kryesisht në krahun e djathtë të Shkumbinit, kurse ato të Gjorg Golemit në të mengjërtin.

Legjendat e Gjorg Golemit njihen në Sopot, Bërzeshtë, Qukës, Polis, Shushicë dhe pothuaj në tërë fshatrat e Shpatit. Në këtë zonë ata jetojnë në një terezi organike, me një përmbajtje të caktuar ngjarjesh, që shtjellohen rreth vendesh, kalash dhe udhëheqësish luftarakë me profil pak a shumë të qartë historik.

Legjendat e paraqesin Golemin, që njihet edhe me emrin Goli i madh a Golemara, si krajl të vendit. Me interes janë të dhënat që sjell tradita për madhështinë e selisë së tij të Sopotit, për rrugët që e lidhin këtë qendër me krahinat rreth e rrotull, për arat e vreshtat që kish nga Ura e Qukësit deri në fund të fushës së Domosdovës, për mbrojtjen me kala e istikame që e rrethonin vendin nga Polisi (nga Kisha e Shenapremtes, Ujt e Ngrohtë e Qafmolla), në Dardhë, Qukës e Bërzeshtë deri në Kryeqytetze, për llagëmet që e lidhin nën dhé kalanë e Sopotit me Polisin, për marrëdhëniet që kish Krajli i Sopotit me Krajlin e Moresë etj. Sipas kujtimeve që ruhen nga tradita gojore, Krajli i Sopotit, Gjorg Golemi ka bërë luftë 40 vjet me "mretin e Turqisë". Luftën e bënte "nji natë në Qafthanë, nji nate ke Ura e Haxhibeqarit". Kështu e kish lodhur kaq shumë dhe i kish shkaktuar kaq humbje ushtrisë turke, sa mbreti ish betuar se po fuste në dorë Sopotin, do ta çonte gjakun deri në shalë të kalit. Pushtimi i Sopotit, sipas legjendave u arrit vetëm me tradhëti, 
në një ditë të vitit, kur Gjorg Golemi me trimat e tij largohej nga kështjella. Por edhe atëherë armiqtë u gjendën përballë grave sopotare, të cilat luftuan si heroina për mbrojtjen e nderit dhe të lirisë së atdheut. Me luftimet e përgjithëshme që zhvilloheshin në Mal-plak, Shkallekurore dhe Qafë Furke merr fund edhe qëndresa heroike e Gjorgj Golemit. Disa gojëdhëna të mbledhura në Polis bëjnë fjalë për mbarimin e tij në burgjet e Edrenesë. (Këtu kur e pyetshin njëherë në vit, si përgiigjej: pa pirë ujë në Sheremet ${ }^{1}$, pa pi ujë në Gurrëshpatë2 , Pa varë armët në lis të gjatë3 daltë. (për të treguar optimizmin e tij, se do të kthehej me doemos një ditë në vendin e vet). Disa gojëdhëna të tjera e paraqesin të larguar së bashku me të birin, Gjel Çelikun në Itali. Ngjarjet e legjendave gjenden të pasqyruara edhe në këngën e njohur të luftës së Sopotit, e cila mbahet si një nga këngët më të vjetra të epikës sonë historike. Në variantin e saj të plotë, kjo këngë është regjistruar në Bërzeshtë. Informacionet gojore e sjellin të njohur këtu që rreth fundit të shek. XVIII (treguesi i saj, Dervish, ka ndekur rreth 1930tës 95 vjeç, ky e ka pas mësuar prej një këngëtari të njohur, një farë Sulë Dylja Kryemadhi, i cili ka pas vdekur gjithashtu mjaft i moshuar, lart nga 100 vjeç, rreth vitit 1860).

Fragmente të saj janë gjendur edhe në Polis e Shpat, ku thuhet se ka qenë kënduar e plotë prej të vjetërve. Kemi të bëjmë pra me një këngë që ka qenë e përhapur në të gjithë territotin ku jeton edhe legjenda. Po në këtë pellg, krahas legjendave dhe këngës së përmendur, jetojnë edhe një numër toponimesh që lidhen organikisht me ngjarjet dhe figurën qendrore të gojëdhënave. Në Polis p.sh. është Guri i Gjorg Golemit, Gjurma e mushkut të Gjergjit, Qaféfurka, Shkallëkurora; në Seltë të Shpatit: Vreshtat e Kralit të Sopotit, Golemja; ku ndahen Selta me Nezharin - Kroi Golem; në Pishkash - Maja e Golemit; në Vasjan - Lisi Degamadh nga ku lajmohej Sopoti, kur vinte ndonjë rrezik nga gryka e Shkumbinit; në kufi të Polisit me Shpatin - Qafa e Shënkollit, ku qëndronin rojet e Gjorg Golemit për mbrojtjen e këtij krahu, një zonë me veprimtari luftarake intensive, një zonë që tërheq vëmendjen si për shkallën e gjerë të rezistencës kundër vërshimit të hordhive osmane ashtu edhe për figurën qendrore që udhëheq këtë rezistencë. Është për t’u shënuar se në asnjë krahinë tjetër të vendit tonë ne nuk gjejmë legjenda që të bëjnë fjalë për bashkëkohës të Skënderbeut me një veprimtari kaq të gjerë luftarake dhe me tipare kaq të qarta historike, sa heroi ynë Gjorg

1 Të gjitha këto elemnte të ruajtura nga tradita zbulojnë: Kroje e gurra të Polisit

2 Kroje e gurra të Polisit

3 Lis i madh po në këtë fshat 


\section{Albanon}

Revistë kulturore

Golemi. Nga këto rrethana mund të konkludohet se tradita popullore për ngjarjet e Sopotit është një jehonë direkte e veprimtarisë luftarake të Gjergj Arianitit, i cili me kryengritjet që udhëhoqi në vitin 1434-1435, 1442 etj., u bë një nga figurat më të njohura të rezistencës shqiptare të shek. XV, pas Skënderbeut.

Në krahun e djathtë të Shkumbinit, nga Rajca deri në Kërrabë, figura qendrore e krijimeve tradicionale është Skënderbeu. Edhe këtu në plan të parë zotërojnë motivet luftarake. Skënderbeu, që vigjëlon në kufijtë e vendit të vet, sapo merr vesh lëvizjen e armikut nga Ohri, çan, sipas legjendës, Shkallën e Guroit të Rajcës, (që njihet edhe sot me emrin, Shkalla e Skenderbeut), godit në befasi ushtritë e tij dhe i bën pluhur. Skënderbeu lufton gjithashtu midis Qukësit e Dardhës, ku gjenden toponime: Guri i Luftës, Shpella e Skënderbeut etj. Po zona e ndeshjeve me të rrepta, gjithashtu sipas traditës lokalizohet në Shushicë, Byshek, Mlizë, Shelcan, Gurabardhë e Letan. Këtu ushtria e Skënderbeut zhvillon luftime të përgjakshme kundër ushtrive turke që ka në krye një nga sulltanët më të përmendur të historisë osmane, Mehmetin II.

Krahas Skënderbeut, legjendat vënë në këtë edhe Kapidanin e Shpatit, Petër Petroshin, i cili nuk përmendet në letërsi. Faza përfundimtare e kësaj beteje zhvillohet në Mlizë, te Druja e Madhe. Prej gjakut të të vramëve, thotë legjenda skuqen ujrëat e Shkumbinit, krymbat e kufomave ngjiten deri në përruan e Shpatit-përfund Shelcanit.

Ekzistenca e këtyre legjandave gjatë luginës së Shkumbinit me të dhënat që sjellin sidomos rreth ashpërsisë së sulmeve të armikut për asgjësimin e Sopotit dhe luftimeve të Mlizës, tregojnë se pushtuesit osmanë kanë shfrytëzuar si një intinerar të rëndësishëm për invazionet e tyre në Shqipëri në rrugën Ohër-Qafthanë-Shkumbin, që përkon me rrugën e vjetër Egnatia, të cilën osmanët janë përpjekur ta shfrytëzojnë edhe lidhur me qëllimin e tyre për daljen në Itali.

Gojëdhënat e tjera që janë mbledhur në krahun e djathtë të Shkumbinit në Mirakë, Labinot, Prapanikë dhe në fshatrat e grykës se Zaranikës, bëjnë fjalë për lëvizjen e ushtrive të Skënderbeut në këto katunde, për pritjen e përcjelljen e tyre për ndonjë fjalë të lënë nga heroi etj. Psh: "Bixëllast e pritën me shumë nder Skënderbeun nga Ceruja asht hudhë në Gur të Zi dhe prej këndej dalë në Griqan e Labinot. Kur ka ardhë Skenderbeu në këto anë populli u mblodhën dhe e pritën në Prapanikë, ke shessi i Qafërenzes. Në Labinot Skënderbeu ka dash të zajë venin me mur nga Guri i Bletës deri 
në Mal të Vashës që të rrit ujt e Shkuminit e të shtojshin lundrat e teposht e terme...” etj. Këto të dhëna që ruhen nga tradita popullore, në një vështrim të parë, duken si krijime të rastit, pa ndonjë vlerë të veçantë. Por në thellësi të tyre, ato sjellin me thjeshtësinë dhe realizimin që karakterizon krijimet popullore, elemente të një realiteti të caktuar historik. Të tilla legjenda nuk kishin se si të lindnin pikërisht në këtë pellg dhe pikërisht me këtë dendësi e përmbajtje pa një bazë historike. Ekzistenca e tyre lidhet me qendresën e vazhdueshme të ushtrive të Skënderbeut në këto vise ku jetojnë legjendat e tij, me marrëdhëniet e ngushta që ka pasur heroi me masat e gjera popullore, që u bënë gurrë e pashteruar e potencialit të tij ekonomik e luftarak. Nga një anë tjetër është për t’u vënë në dukje se legjendat e Skënderbeut të Grykës së Zaranikës, paraqesin vazhdimësi me ato që jetojnë në malësi të Tiranës (Tomadhe e Benë). Ky kordon gojëdhënash që vjen nga Kruja dhe zgjatet në mënyrë të pakëputur nëpër këto zona me kalanë e Skënderbeut në Shëngjin, me elemente, toponime etj., në Bosh Shëngjergj, Fag e Kllojkë tregon se Skënderbeu ka rrahur rregullisht këtë rrugë për lëvizjen e trupave të tij, që derdhte në Elbasan kundër ushtrive osmane.

\section{Legjenda të tjera flasin për vetitë e jashtëzakonshme fizike morale të Skënderbeut}

Fantazia e gjallë popullore, e frymëzuar nga gjestet luftarake të heroit dhe fitoret e tij, e idealizoi me përpjestime gjigande forcën e krahut dhe të shpatës së Skënderbeut. Barleti thotë: "Trimëri e kryetrimit u dukej të gjithëve e pamposhtur...pothuaj asnjë goditje e tij nuk shkonte kot". Në të tilla rrethana, forca e mrekullueshme e shpatës së Skënderbeut, në legjendat tona është dhënë me prerjen e Shkëmbit të Rrajcës, me hapjen e llagameve të nëndheshme si ai i shpellës së Letanit që lidhte, sipas gojëdhënave: Elbasanin me kalatë e rrethit të Dibrës, ku ai lëvizte për daljet e papritura dhe sulmet e befasishme kundër armikut. Shprehje e admirimit për aftësitë e rralla të heroit, i cili dinte të gjente sipas rastit taktikën më të përshtatshme për të siguruar fitoren, për sulmet e tij të rrufeshme e për çarjen e rrethimeve janë gjithë ato tregime që flasin për hedhjen e Skënderbeut, p.sh nga Bixëlleja në Labinot, nga Mollashi në Cërujë etj., si dhe gjurmët e kalit të tij nëpër shkëmbinj të zonave të ndryshme të rrethit tonë. Skënderbeu është një hero vigan që, kur luan me shokët gurapeshës, i hedh gurët nga Mali i Belicës në Prapanikë, siç tregojnë, sipas legjendës vgjollat e Skënderbeut që gjenden në këtë fshat, ai rrxon shkëmbij nga shpella që mban emrin e tij në Qukës të Librazhdit, për 


\section{Albanon}

Revistë kulturore

të asgjësuar armiqtë, shtron tryeza të gurta ciklopike si sofrën e Pishkashit, etj.

Tradita gojore e rrethit tonë ruan edhe elemente të tjera interesante, sidomos në fushën e Toponomastikës, që mund të bëhen pikënisje për qartësimin e problemeve të ndryshme historike të kësaj periudhe. Kështu lidhur me qytetin e Valmit, tërheqin vëmendje emrat Guri Valmorit a Guri $i$ Valmet në Çermenikë, për lokalizimin e Fushës së Savrës, ku ngriti kampin Fatihu, kur ndërtoi kështjellën e Elbasanit; paraqesin interes rastet e ndryshme të emrit Sare që hasen në Dardha (Sarat, Sar'e mage, Savra e Muçanit, për të cilën bën fjalë prof. Dh.S.Shuteriqi ${ }^{4}$, në Shelcan Sàra - Burim), Kabash etj., për gjendjen e dikurshme të fshatrave tona dhe pasojat shkatërrimtare të luftrave - Vile: Vila (Bërzeshtë), Vilani (Sopot), Viles Prroi i Vilzës (Xhyrë e Polis), emrat Katuni Plak (Qukës e Dardhë), Katuni Vjetër (Polis e Shushicë), që tregojnë sot troje të braktisura pranë fshatrave përkatës. Është për t’u theksuar këtu se arsimtarëve u bie detyra për kërkime sistematike në drejtim të këtyre elementeve, që na janë ruajtur me kaq dashuri e këmbëngulje nga populli dhe për studimin e kujdesshëm të tyre.

Nga të dhënat e mësipërme, shihet se legjendat e toponimet e rrethit të Elbasanit i bëjnë jehonë ngjarjeve historike që patën si teatër të shtjellimit të tyre, krahinat e ndryshme të kësaj treve. Nëpërmjet këtyre krijimeve tradicionale jetojmë kuadrin e madhërishëm të ngjarjeve të kësaj periudhe. Të dhënat rreth luftimeve të Mlizës e atyre të Sopotit, ku armiku me masakrat e tij u jep shkas legjendave të tilla si ajo e Liqenit të Kuq, dëshmojnë për egërsinë e një pushtuesi të tërbuar. Përpara sulmeve sistematike dhe furisë së një armiku të tillë, shkëlqen heroizmi i popullit tonë, që lufton me vendosmëri të patundur për mbrojtjen e vendit dhe të lirisë. Legjendat dhe këngët për luftimet e Sopotit, krahas përpjestimeve të një lufte të madhe, ku armiku vjen si mizëria, na ka ruajtur një nga faqet më të lavdishme të heroizmit tradicional të grave tona me madhështinë e qëndresës së sopotarëve. Patriotizmi i masave popullore, i dashurisë së thellë për vendin dhe urrejtjen e pakufishme ndaj kundërshtarit, përshkron pothuajse të gjitha gojëdhënat e kësaj periudhe.

Sulltani "qan me lot" se ish përpjekur vite të tëra për të vënë në dorë kështjellat e rezistencës shqiptare që ishin bërë tani simbole të rezistencës evropiane, dhe s'ia kishte dalë dot në krye qüllimeve të tij me anë të armëve. Të dhënat e traditës vërtetojnë ato që thonë vetë kronistët osmanë se: "shqiptarët luftojnë si tigra kthetërfortë....edhe luftëtari më $i$ dobët $i$ tyre është nga më trimat e fushë

Dh.S. Shuteriqi, Aranitët, Studime historike, 197, nr. 1, f. 66 
së luftës...ata shpërndajnë zjarr si vetëtima me ushtarët e tyre, shpojnë edhe gurin me shigjetat që hedhin". Patriotizmin e masave popullore e ndjejmë edhe në qëndrimin e njerëzve të thjeshtë, që punojnë ditë e natë së bashku me Skënderbenë, si në rastin e hapjes e shkëmbenjve të Rrajcës, për t’i prerë rrugën ushtrive të Ballabanit, e shohim në dashurinë që tregohet nga masa fshatare e këtyre anëve ku mblidhen për të pritur heroin në sheshin Qafërenzës, në legjendat e shumta që flasin për furnizimin e ushtrisë së tij në Bixëllenjë, Labinot etj..., e kuptojmë nga vendosmëria që tregon populli në përballimin e sakrificave, kur, edhe pse i mungon buka, edhe kur shohin se po u lindin fëmijë pa dritën e syve, nga mungesae krypës, siç thotë legjenda, nuk tërhiqen asnjëherë nga lufta.

Këto fitore madhështore që u arritën kundër ushtrive osmane, të cilat mbaheshin si më të fuqishmet e kohës, qenë fryt i dashurisë së thellë për vendin, i urrejtjes së pakufishme kundër armikut, i aftësive dhe vlerave të mëdha morale të gjithë popullit.

Gojëdhënat dhe këngët e rrethit të Elbasanit për Skënderbeun dhe bashkëkohësit e tij, janë pjesë përbërëse të traditës që ka krijuar populli ynë në përgjithësi për këtë periudhë të shkëlqyer të historisë sonë.

Duke ruajtur lavdinë e përpjekjeve dhe të luftrave të mëdha ngadhnjimtare, këto krijime popullore mbetën përmes shekujve si një përmendore fitoresh, si një gurrë e pashtershme që ka rritur vazhdimisht nëpër shekuj ndërgjegjen patriotike të luftrave për liri dhe pavarësi. Periudha e rëndë e robërisë, nuk mundi t'i shlyejë nga mendja dhe zemra e popullit kujtimet e kohës së Skënderbeut. Ata jetuan nëpër shekuj si një shfaqje e gjallë e shpirtit epik tona popullore, e vullnetit të tyre për liri, si një flamur i madh lavdie që frymëzonte për beteja të vazhdueshme çlirimtare. 